\title{
MEASURES TAKEN FOR SPACING OF PREGNANCY AS PERFORMANCE INDICATORS OF FAMILY WELFARE AND MCH CARE
}

\author{
Sandhya Dixit ${ }^{1}$
}

${ }^{1}$ Assistant Professor, Department of Obstetrics and Gynaecology, Osmania Medical College, Hyderabad, Telangana State.

\section{ABSTRACT}

Adequate spacing of pregnancy results in reduced pathology of pregnancy namely,

- Anaemia and its adverse consequences including blood transfusion hazards.

- Hypertensive diseases and its complications including life-threatening eclampsia, myocardial failure, cerebrovascular accidents, HELLP and DIC.

- Nutritional deficiencies.

- Reduced incidence of IUGR, preterm labour, chronic foetal hypoxia.

- Thereby leading to reduced caesarean deliveries along with operative adverse eventualities.

Mother is psychologically and physically fit for the new born, financially ready and motivated for regular ANC care.

The first child will have its due for full lactation, mother's undivided attention and well nourished.

\section{KEYWORDS}

Spacing of Pregnancy, Foetal Hypoxia, ANC Care, MCH Care.

HOW TO CITE THIS ARTICLE: Dixit S. Measures taken for spacing of pregnancy as performance indicators of family welfare and MCH care. J. Evolution Med. Dent. Sci. 2016;5(99):7307-7309, DOI: 10.14260/Jemds/2016/1654

\section{BACKGROUND}

Pregnancy is a physiological burden on a woman's system, so much so that it alters the milieu interior, mimics pathology and leads to morbidity and mortality sometimes. Every organ function in the body of a woman changes due to pregnant status to accommodate additional work, i.e. sustaining foetus and placenta. In addition pregnancy endocrine profile influences the routine and regular bodily reflexes, sometimes leading to near fatality. A pregnant mother is exposed to diseases peculiar to pregnancy, which may end up as debility and death. Common diseases of pregnancy, ex. hypertensive disorders, diabetes mellitus, liver diseases or infective disorders will accentuate the risk. Anaemia merits a special mention, since it is the main killer of pregnant mothers.

$\mathrm{PPH}, \mathrm{APH}$, instrumental deliveries and caesarean section threaten the lives of the pregnant mothers as well as lead to disability or morbidity. The incidence of maternal mortality and morbidity is around $30 \%$ if a pregnancy is spaced less than 2 years. Incidence of perinatal mortality and morbidity is higher in too close pregnancies.

A pregnant mother dares all risks to beget a child and keeps on desiring for more.

Reproduction is every woman's fundamental right and there is no limit to the numbers if she is intent on it. We can

Financial or Other, Competing Interest: None.

Submission 19-08-2016, Peer Review 27-09-2016,

Acceptance 03-10-2016, Published 12-10-2016.

Corresponding Author:

Dr. Sandhya Dixit,

Plot No. 130, Sriram Nagar Colony,

Near Green Water Tank,

Vanasthalipuram,

Hyderabad -500072 .

E-mail: sandhyadixit9@yahoo.com

DOI: $10.14260 /$ jemds $/ 2016 / 1654$

\section{(c) $(1)$}

counsel, explain the risks of multiparity and persuade them but we cannot coerce them.

As conscientious obstetricians, we have to provide allround health care to the aspiring mothers irrespective of the associated risks and guide them appropriately. In this context, WHO has some guidelines regarding spacing of pregnancies.

According to WHO, Maternal and Child Health Services can be defined as "promoting, preventing, therapeutic or rehabilitation facility or care for the mother and child."(1) Five areas that are essential to MCH policies and practice are,(2)

- Scientific basis of MCH and public health

- Methodological and analytical skills

- Management and communication skills

- Policy and advocacy skills

- Values and ethics

Healthy spacing and timing of pregnancy (HS and TP) is advocated by WHO for best foeto-maternal outcome. A minimum of two years and an optimum of three years would be most beneficial to the mother for the following reasons. Studies show that when the length of time between two births in a family is less than two years, the new-born on average is twice as likely to die in infancy as might a child born after a longer birth-interval. ${ }^{3}$ This applies not only to the first year of life, but adversely affects the child's survival chances for at least the first four years of life.(3)

1. The first child will get full period of lactation as is due to it.

2. The first child will get the undivided attention of the parents along with tender loving care.

3. The economic burden would be half the amount, which they would have for 2 children within 2 or 1 year.

4. Mother would get adequate time for recuperation from pregnancy, parturition and surgery if any. 
5. The physical, physiological, biochemical and psychological burden and changes of pregnancy will require 2 to 3 years to revert back to near pre-pregnancy status.

6. Mother will be mentally ready to undertake a pregnancy usually after 2 years of previous pregnancy.

7. At the age of 3 years the child will be more amenable for oral instructions, will understand and implement its mother's orders and advices. Three-year child understands about safety and precautions, thus allowing the mother to have more free time.

8. The incidence of PROM, preterm labour, pathology of pregnancy is low in an adequately spaced pregnancy, i.e. > 2 years.

The above points emphasise the wellbeing of the first child before deciding for the next pregnancy. Hence, spacing of pregnancies is essential for the mother, her child and her yet to be born next child.

The amount of time between a live birth and the beginning of the next pregnancy or the Interpregnancy Interval (IPI) can impact the health of both mother and infant. Short IPI's (generally defined as less than 18 months) ${ }^{1,2}$ have been associated with adverse perinatal outcomes including preterm birth, low birth weight and small size for gestational age ${ }^{3}$ as well as adverse maternal outcomes including uterine rupture 4 among women attempting a vaginal birth after a caesarean, placental abruption and placenta previa. There are various post-partum contraceptive choices.

\section{Various Post-Partum Contraceptive Choices}

\begin{tabular}{|c|c|c|}
\hline 1. & Condoms & $\begin{array}{c}\text { Temporary } \\
\text { Contraception }\end{array}$ \\
\hline 2. & IUCD's & Same As Above \\
\hline 3. & Progesterone-Only Pills & Same As Above \\
\hline 4. & Injectables Progesterone & Same As Above \\
\hline 5. & Implants & Same As Above \\
\hline 6. & Natural Methods & Same As Above \\
\hline 7. & $\begin{array}{c}\text { Male and Female Sterilisation } \\
\text { Operations }\end{array}$ & $\begin{array}{c}\text { Permanent } \\
\text { Contraception }\end{array}$ \\
\hline
\end{tabular}

Different types of contraceptives
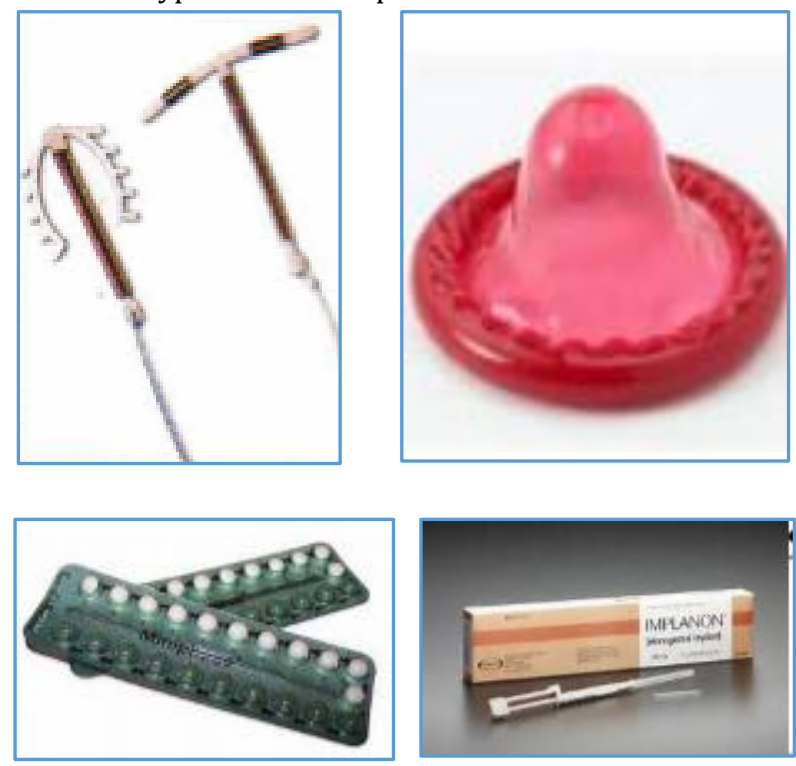

\section{Contraceptive method choice}

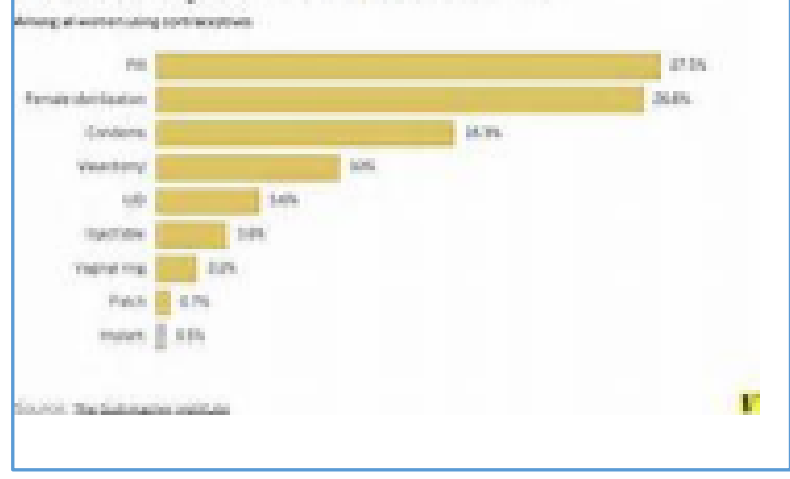

Condoms with its high failure rates can be given to those whose spouses may go abroad after some time or works at some distant place. It is coital dependent and needs partner's cooperation every time. Dislike for its use and stress in using it are sometimes complained.

\section{Hormone Contraception}

The present day formulations are promising. Newer progestins, pops followed later by low and ultralow dose oestrogen combinations, vaginal hormonal rings are making contraception more feasible and have least side effects. Return to fertility is prompt when so desired.

WHO's medical eligibility criteria guides us to right selection of the clients and compatible prescriptions, thereby further reducing adverse complications.

Minor problems exist like needing repeated visits to Health Centres for the stock and questionable compliance for regular daily intake.

IUCD is another good choice for an effective (98.5\%), longterm, reversible and temporary contraception.

The National Programme of IUCD training encompasses training of doctors and nurses in IUCD insertions all over the country.

Repositioning of IUCD training is a six-day programme. It imparts thorough know-how of regular, i.e. interval IUCD insertion along with hands on experience under supervision.

PPIUCD training programme is a three-day programme and involves obstetricians and staff nurses. It is a specialist training, where post-partum insertion of an IUCD is taught.

Types of PPIUCD Insertions

\begin{tabular}{|c|c|c|c|}
\hline $\begin{array}{c}\text { Post } \\
\text { Placental }\end{array}$ & $\begin{array}{c}\text { Immediately } \\
\text { after Delivery of } \\
\text { Placenta within } \\
\text { 10 mins. }\end{array}$ & $\begin{array}{c}\text { Best } \\
\text { Option }\end{array}$ & $\begin{array}{c}\text { Lowest } \\
\text { Expulsion } \\
\text { Rate }\end{array}$ \\
\hline $\begin{array}{c}\text { Post } \\
\text { natal/post- } \\
\text { partum }\end{array}$ & $\begin{array}{c}\text { Within } 48 \text { hrs. of } \\
\text { delivery }\end{array}$ & & \\
\hline $\begin{array}{c}\text { Intra- } \\
\text { caesarean }\end{array}$ & $\begin{array}{c}\text { Through the } \\
\text { caesarean } \\
\text { incision }\end{array}$ & & \\
\hline
\end{tabular}

Post-partum IUCD insertions are of three kinds.

Post-placental, where IUCD is inserted immediately after placental delivery within ten minutes, "Placenta out - IUCD in."

Postnatal/post-partum where IUCD is inserted after ten minutes of placental delivery and within $48 \mathrm{hrs}$. 
Intra-caesarean during the LSCS operation through the uterine incision after placental delivery manually.

A special Kelly's forceps, which is longer than sponge holding forceps with a curve at the upper end to facilitate IUCD insertion is used in vaginal insertion.

In conclusion, there is an urgent need for a viable, longstanding, reversible contraception in our country which has more young population, more young couples who need temporary contraception most urgently.

Our prime minister says, India has demography and demand where young population with varied skills and strengths outnumber others.

This, if extrapolated to health services, obviously contraception and family welfare is the urgent need of the hour.

\section{REFERENCES}

1. DHHS Home $>$ Division of Public Health Services $>$ Bureau of Community Health Services $>$ Maternal \& Child Health.

2. http://www.mchb.hrsa.gov/training/projects.asp?progra $\mathrm{m}=17$. The Maternal and Child Health Bureau (MCHB) is a part of the Human Resources and Services Administration (HRSA) of the United States (US) Department of Health and Human Services (DHHS).

3. Maternal And Child Health Care. Sabeena shashidharan assistant lecture, lourde college of nursing, family planning program number: 1-302-744-4552 Revised: 01/2011 Page 1 of 1 . 